\title{
Outcomes of cataract surgery in diabetic patients: results of the Pan American Collaborative Retina Study Group
}

\author{
Resultados da cirurgia de catarata em pacientes diabéticos: resultados do \\ Pan-American Collaborative Retina Study Group
}

Roberto Gallego-Pinazo ${ }^{1}$, Rosa Dolz-Marco ${ }^{1}$, Maria Berrocal ${ }^{2}$, Lihteh Wu ${ }^{3}$, Mauricio Maia ${ }^{4}$, Martín Serrano ${ }^{5}$, Arturo Alezzandrini ${ }^{6}$, J. Fernando Arévalo 7,8 , Manuel Díaz-Llopis ${ }^{1,9}$, for the Pan-American Collaborative Retina Study Group (Pacores)*

\begin{abstract}
Purpose: This study was designed to evaluate the visual and anatomical outcomes after cataract surgery in diabetic patients with different intraoperative therapeutic strategies.

Methods: The research design comprised of a multicentric, retrospective, interventional study conducted at 6 centers in Argentina, Brazil, Costa Rica, Puerto Rico, Spain, and Venezuela. We included 138 diabetic patients with at least 6-month follow-up following phacoemulsification and intraocular lens implantation. Best-corrected visual acuity (BCVA) and central subfield thickness were collected at baseline and at 1-, 2-, 3-, and 6-month follow-up. Of these, 42 cases were not treated with any intraoperative coadjuvant medication (Group 1), 59 patients received intraoperative bevacizumab (Group 2) and 37 patients received intraoperative triamcinolone (4 mg/0.1 ml) (Group 3).

Results: The mean logMAR [ \pm standard deviation (SD)] BCVA improved from 0.82 $( \pm 0.43)$ at baseline, to $0.14( \pm 0.23)$ at 6 -month follow-up $(p<0.001)$ in Group 1 ; from $0.80( \pm 0.48)$ to $0.54( \pm 0.45)(p<0.001)$ in Group 2; and from $1.0( \pm 0.40)$ to $0.46( \pm 0.34)(p<0.001)$ in Group 3. The mean central subfield thickness increased from $263.57 \mu \mathrm{m}( \pm 35.7)$ at baseline to $274.57 \mu \mathrm{m}( \pm 48.7)$ at 6 -month follow-up $(p=0.088)$ in Group 1; from $316.02 \mu \mathrm{m}( \pm 100.4)$ to $339.56 \mu \mathrm{m}( \pm 145.3)(p=0.184)$ in Group 2; and from $259.18 \mu \mathrm{m}$ ( \pm 97.9$)$ to $282.21 \mu \mathrm{m}( \pm 87.24)(\mathrm{p}=0.044)$ in Group 3. Conclusions: Diabetic patients may significantly benefit from cataract surgery. This study provides evidence to support the use of intravitreal triamcinolone or bevacizumab at the time of cataract surgery in cases with pre-existent diabetic macular edema or moderate-severe non-proliferative diabetic retinopathy.
\end{abstract}

Keywords: Diabetic retinopathy; Macular edema; Cataract extraction; Intraoperative care; Phacoemulsification; Lens implantation, intraocular; Antibodies, monoclonal; Multicenter study

\section{RESUMO}

Objetivo: Avaliar os resultados visuais e anatômicos após a cirurgia de catarata em pacientes diabéticos com estratégias terapêuticas intraoperatórias diferentes.

Métodos: Estudo multicêntrico, retrospectivo, de intervenção realizado em 6 centros da Argentina, Brasil, Costa Rica, Porto Rico, Espanha e Venezuela. Foram incluídos 138 pacientes diabéticos com pelo menos 6 meses de seguimento após facoemulsificação com implante de lente intraocular. Acuidade visual melhor corrigida (BCVA) e a espessura subcampo central (CST) foram coletadas no início e em 1, 2, 3 e 6 meses de seguimento. Destes, 42 casos não foram tratadas com qualquer co-adjuvante de medicamentos intra-operatório (Grupo 1), 59 pacientes receberam bevacizumab intraoperatório (Grupo 2), e 37 pacientes receberam triancinolona intraoperatória (4 mg/0,1 ml) (Grupo 3).

Resultados: A média logMAR ( \pm desvio-padrão [DP]) BCVA melhorou de 0,82 $( \pm 0,43$ ) no início do estudo, para $0,14( \pm 0,23)$ aos 6 meses de seguimento $(p<0,001)$ no Grupo 1 ; de 0,80 $( \pm 0,48)$ para 0,54 $( \pm 0,45)(p<0,001)$ no Grupo 2; e de 1,0 $( \pm 0,40)$ para 0,46 $( \pm 0,34)(p<0,001)$ no Grupo 3. A CST média aumentou de $263,57 \mu \mathrm{m}( \pm 35,7)$ na linha de base para $274,57 \pm 48,7 \mu \mathrm{m}$ em 6 meses acompanhamento $(p=0,088)$ no Grupo 1; de 316,02 $\mu \mathrm{m}( \pm 100,4)$, para 339,56 $\mu \mathrm{m}( \pm 145,3)(p=0,184)$ no Grupo 2; e de 259,18 $\mu \mathrm{m}$ $( \pm 97,9)$, para $282,21 \mu \mathrm{m}( \pm 87,24)(p=0,044)$ no grupo 3 .

Conclusões: Pacientes diabéticos podem se beneficiar significativamente da cirurgia de catarata. Este estudo parece fornecer evidências para apoiar o uso de triancinolona intravítrea ou bevacizumab no momento da cirurgia de catarata em casos com edema macular diabético preexistente (DME) ou retinopatia diabética não-proliferativa moderada a grave.

Descritores: Retinopatia diabética; Edema macular; Extração de catarata; Cuidados intraoperatórios; Facoemulsificação; Implante delente intraocular; Anticorpos monoclonais; Estudo multicêntrico

\section{INTRODUCTION}

Diabetic retinopathy (DR) represents a leading cause of moderate and severe vision loss within the working-age population in developed countries ${ }^{(1)}$. Advanced proliferative DR complicated by vitreous hemorrhage or tractional retinal detachment is responsible for most cases of severe loss of vision, but diabetic macular edema (DME) is the most prevalent cause of moderate vision loss ${ }^{(2)}$. It is known that hyperglycemia causes damage to the retinal vascular endothelium, resulting in increased vascular permeability, exudation, and accumulation of extracellular fluid and proteins within the macula, hemorrhages,

Department of Ophthalmology, University and Polytechnic Hospital La Fe, Valencia, Spain.

Department of Ophthalmology, University of Puerto Rico, San Juan, Puerto Rico.

${ }^{3}$ Instituto de Cirugía Ocular, San Jose, Costa Rica.

${ }^{4}$ Department of Ophthalmology and Visual Sciences, Escola Paulista de Medicina (EPM), Universidade

Federal de São Paulo (UNIFESP), São Paulo, Brazil.

${ }^{5}$ Clinica Oftalmologica Centro Caracas and the Arevalo-Coutinho Foundation for Research in Ophthalmology, Caracas, Venezuela.

thalmology, Caracas, Venezuela.

Cátedra de Oftalmologia, Universidad de Buenos Aires, Buenos Aires, Argentina.

Vitreoretinal Division, The King Khaled Eye Specialist Hospital, Riyadh, Kingdom of Saudi Arabia.

${ }^{8}$ Retina Division, The Wilmer Eye Institute, Johns Hopkins University, Baltimore, USA

${ }^{9}$ Faculty of Medicine, University of Valencia, Valencia, Spain.

* For a complete listing of participating members of PACORES see Appendix.

Funding: No specific financial support was available for this study.

Disclosure of potential conflicts of interest: None of the authors have any potential conflicts of interest to disclose.

Corresponding author: Rosa Dolz-Marco. Department of Ophthalmology - University and Polytechnic Hospital La Fe. Bulevar Sur - s/n - Valencia - 46026 - Spain - E-mail: rosadolzmarco@gmail.com 
microaneurysm formation, and capillary closure ${ }^{(3,4)}$. Hypoxia has been linked to retinal neovascularization but has also been associated with $\mathrm{DME}^{(3)}$.

Focal or grid macular laser photocoagulation (MLP) were previously the mainstay of treatment for DME, but the advent of intravitreal inhibitors of the vascular endothelial growth factor (VEGF) has recently changed the therapeutic strategies for DME. Several studies have demonstrated significantly better visual outcomes with intravitreal injections of ranibizumab alone or in combination with $M L P^{(3-6)}$. Intravitreal injections of corticosteroids (triamcinolone and dexamethasone implant) have also achieved positive functional and anatomical results in the treatment of DME; however, local safety issues, such as cataract progression or intraocular pressure increase, must be considered for this treatment ${ }^{(5,7)}$.

Visual outcomes following cataract surgery in diabetic patients have been correlated with the presence of DME and the severity of DR at the time of the surgery. It is controversial whether phacoemulsification may trigger the progression of DR and DME compared with the natural history of the disease $\mathrm{e}^{(8-9)}$.

The purpose of the present study was to evaluate the functional and anatomical outcomes after cataract surgery in diabetic patients managed with different therapeutic approaches.

\section{METHODS}

This retrospective, multicentric, interventional study was conducted at 6 different centers in Argentina, Brazil, Costa Rica, Puerto Rico, Spain and Venezuela between December 2009 and December 2012. The clinical charts of all diabetic patients who underwent cataract surgery were retrospectively reviewed after obtaining institutional review board approval.

The inclusion criteria were patients over 18 years old diagnosed with diabetes mellitus who had undergone uncomplicated phacoemulsification with intraocular lens implantation and had at least 6 months of follow-up after phacoemulsification and intraocular lens implantation. Patients were excluded if there was evidence of any retinal disease other than diabetic retinopathy. Patients showing subretinal fibrosis or fibrous metaplasia of the retinal pigment epithelium, or vitreo-macular traction that may limit the visual function, were also excluded.

Patients were classified into 3 groups depending on the use of co-adjutant medications during cataract surgery. The decisions about whether to administer any co-adjuvant therapy, and the choice of the drug if administered, were left to the discretion of the treating surgeon. Patients in Group 1 did not receive any co-adjuvant therapy; patients in Group 2 received an intraoperative intravitreal injection of bevacizumab (1.25 mg/0.05 ml); and patients in Group 3 received an intravitreal injection of triamcinolone $(4 \mathrm{mg} / 0.1 \mathrm{ml})$ intraoperatively.

Best-corrected visual acuity (BCVA) measured by Early Treatment Diabetic Retinopathy Study (ETDRS) charts expressed in a logarithm of minimum angle of resolution (logMAR) and central subfield thickness (CST) automatically measured by optical coherence tomography (OCT) were collected at baseline and 1-, 2-, 3- and 6-months follow-up visits. The types of OCT used were Cirrus HD-OCT (Carl Zeiss, Dublin, CA, USA) and Spectralis OCT (Heidelberg Engineering, Heidelberg, Germany). In all cases, a quality of the OCT scans of at least 7/10 was required, and all the images were reviewed in order to avoid any misalignment. The presence of DME was defined as the evidence of retinal thickening in the OCT images, and it was classified as cystoid, diffuse macular thickening (DMT) or neurosensory detachment. A fluorescein angiography was performed and analyzed at baseline to assess the presence of focal or diffuse macular edema and to rule out the presence of macular ischemia.

The data were collected in a Microsoft Office Excel 2007 spreadsheet (Microsoft Corporation, Unterschleissheim, Germany) and statistically analyzed by SPSS Software version 21.0 (SPSS Inc, Chicago, IL, USA).

\section{RESULTS}

\section{BASELINE CHARACTERISTICS}

The clinical charts of 138 eyes of 138 patients ( 72 male, 66 female) were reviewed. The mean age was 66.8 years (standard deviation [SD \pm ] 8.59; range: 38-96). We found coexistence of systemic arterial hypertension in 21 patients (14.2\%), a prior history of stroke in 6 patients (4\%) and myocardial infarction in 10 patients (6.8\%). The mean time since the initial diagnosis of diabetes had been established was 16.4 years (SD \pm 8.32 ; range: $38-96$ ). Fifty-two patients (35.1\%) were receiving treatment with insulin, 45 patients (30.4\%) with oral hypoglycemic agents, 34 patients (23\%) used insulin in combination with oral hypoglycemic agents and 7 patients (4.7\%) were controlled only with diet.

The baseline retinal status was normal in 26 patients (18.8\%); mild non-proliferative diabetic retinopathy (NPDR) was found in 24 patients (17.4\%); moderate NPDR in 18 patients (13\%); and severe NPDR in 21 patients (15.2\%). On the other hand, inactive proliferative diabetic retinopathy (PDR) without laser therapy treated with anti-VEGF therapy ${ }^{(10)}$ was present in 18 patients $(13 \%)$; inactive PDR treated with laser was present in 10 patients (7.2\%); 5 patients (3.6\%) presented with active PDR without previous laser therapy and 16 patients (11.6\%) presented with active PDR with laser treatment. Previous treatments received by the 138 patients included in the study were intravitreal bevacizumab (46 patients, 33.3\%), with a mean number of 3.1 injections (range: 1-13); intravitreal triamcinolone injections (21 patients, 15.2\%); MLP (48 patients, 34.8\%); and 9 patients (6.5\%) had previous pars plana vitrectomy (PPV) with internal limiting membrane peeling (6 patients, $4.3 \%$ ) or without it (3 patients, 2.2\%). The baseline characteristics by groups are summarized in table 1.

Overall we found a statistically significant and positive correlation between the final BCVA with the baseline BCVA $(p<0.001, r=0.33)$. In addition, we report a statistically significant but negative correlation between the final BCVA and the duration of diabetes $(p=0.002$, $r=-0.31)$, level of hemoglobin A1c (HbA1c) ( $p=0,044 ; r=-0.18)$, grade of diabetic retinopathy at baseline examination $(p<0.001, r=-0.44)$ and prior treatment with triamcinolone $(p=0.001, r=-0.19)$ or anti-VEGF drugs $(p=0.027, r=-0.28)$. Final CST in the OCT was significantly and positively correlated with baseline CST $(p<0.001, r=0.39)$, history of myocardial infarction $(p=0.018, r=0.20)$, level of $\mathrm{HbA1c}(p=0,042$, $r=0.19)$, prior treatment with triamcinolone $(p=0.003 ; r=0.43)$ and prior treatment with anti-VEGF drugs $(p<0.001, r=0.25)$ or MLP $(p=0.04, r=0.17)$.

No co-adjuvant intraoperative treatment was administered to 42 patients (Group 1). Fifty-nine patients were treated with intravitreal bevacizumab intraoperative (Group 2), and 37 patients were injected intraoperatively with triamcinolone (Group 3).

\section{Group 1: Without Co-ADJUVANT therapy}

Forty-two cases were included in this group. At baseline, 3 patients (7.1\%) showed DMT, but no signs of cystoid DME or neurosensory detachment were found in the other 39 patients (92.9\%). The FA images showed focal edema in two patients (4.7\%) and diffuse edema in one patient (2.4\%). No signs of retinal or macular ischemia were reported in these patients. The retinal status was normal in 23 patients (54.8\%); mild NPDR was found in 6 patients (14.3\%); moderate NPDR in 3 patients (7.1\%); severe NPDR in two patients (4.8\%); and PDR was present in 8 patients (19\%).

The mean logMAR BCVA improved significantly from 0.82 (SD \pm 0.43 , median: 0.75$)$ at baseline, to 0.20 (SD \pm 0.26 , median: 0.10$)$ at 1 -month of follow-up $(p<0.001)$; and maintained the significant visual gain compared with baseline at 2 months of follow-up (mean: 0.16, SD \pm 0.25 , median: 0.05; $\mathrm{p}<0.001$ ), and at 3 months of follow-up (Mean: $0.14, S D \pm 0.23$, median: 0.0; $p<0.001)$. At 6 months of follow-up, the mean BCVA was 0.14 (SD \pm 0.23 , median: 0.0 ), still showing statistically significant differences from baseline $(p<0.001)$. 
Table 1. Baseline characteristics

\begin{tabular}{|c|c|c|c|c|}
\hline & Group 1 & Group 2 & Group 3 & $\mathbf{p}$ \\
\hline Number of patients & 42 & 59 & 37 & \\
\hline $\operatorname{Sex}, n(\%)$ & & & & 0.911 \\
\hline Male & $21(50)$ & $32(54.2)$ & $19(51.4)$ & \\
\hline Female & $21(50)$ & $27(45.7)$ & $18(48.6)$ & \\
\hline Age $($ mean $+S D)$, years & $68.1 \pm 8.3$ & $65.5 \pm 10.1$ & $65+5.8$ & 0.433 \\
\hline Mean BCVA: baseline & 0.21 & 0.25 & 0.14 & 0.008 \\
\hline Mean OCT scores: baseline, microns & 263.57 & 316.01 & 259.2 & 0.001 \\
\hline Hypertension, n (\%) & $16(38.1)$ & $12(20.3)$ & $2(5.4)$ & $<0.001$ \\
\hline History of stroke, n (\%) & $3(7.1)$ & $3(5.1)$ & $0(0)$ & 0.284 \\
\hline History of myocardial infarction, n(\%) & $3(7.1)$ & $6(10.7)$ & $1(2.7)$ & 0.395 \\
\hline Systemic glycemic control, n (\%) & & & & $<0.001$ \\
\hline Diet & $6(14.3)$ & $1(1.7)$ & $0(0)$ & \\
\hline Oral hypoglycemiants & $8(19)$ & $37(62.7)$ & $7(18.9)$ & \\
\hline Insulin & $18(42.9)$ & $16(27.1)$ & $11(29.7)$ & \\
\hline Combined therapy & $10(23.8)$ & $5(8.5)$ & $19(51.4)$ & \\
\hline Time to diagnosis of DM, years & 12.1 & 16.1 & 21 & $<0.001$ \\
\hline $\mathrm{HbA1c}, \%$ & 7.13 & 8.14 & 8.36 & 0.004 \\
\hline Grade of DR, n (\%) & & & & $<0.001$ \\
\hline Normal & $23(45.8)$ & $3(5.1)$ & $0(0)$ & \\
\hline Mild NPDR & $6(14.3)$ & $15(25.4)$ & $3(8.1)$ & \\
\hline Moderate NPDR & $3(7.1)$ & $10(16.9)$ & $5(13.5)$ & \\
\hline Severe NPDR & $2(4.8)$ & $10(16.9)$ & $9(24.3)$ & \\
\hline Inactive PDR, no laser & $8(19)$ & $5(8.5)$ & $5(13.5)$ & \\
\hline Inactive PDR, laser & $0(0)$ & $0(0)$ & $0(0)$ & \\
\hline Active PDR, no laser & $0(0)$ & $1(1.7)$ & $4(10.8)$ & \\
\hline Active PDR, laser & $0(0)$ & $5(8.5)$ & $11(29.7)$ & \\
\hline \multicolumn{5}{|l|}{ Prior treatment, n (\%) } \\
\hline Anti VEGF injection & $7(16.7)$ & $36(55.9)$ & $3(8.1)$ & $<0.001$ \\
\hline Triamcinolone injection & $1(2.4)$ & $19(32.2)$ & $1(2.7)$ & $<0.001$ \\
\hline Macular laser therapy & $4(9.5)$ & $41(69.5)$ & $2(5.4)$ & $<0.001$ \\
\hline PPV & $5(11.9)$ & $4(6.8)$ & $1(2.7)$ & 0.475 \\
\hline
\end{tabular}

ANOVA test.

$\mathrm{SD}=$ standard deviation; $\mathrm{BCVA}=$ best-corrected visual acuity; $\mathrm{OCT}=$ optical coherence tomography; $\mathrm{DM}=$ diabetes mellitus; $\mathrm{Hb}=$ hemoglobin; $\mathrm{DR}=$ diabetic retinopathy; $\mathrm{NPDR}=$ non-proliferative diabetic retinopathy; $\mathrm{PDR}=$ proliferative diabetic retinopathy; $\mathrm{VEGF}=$ vascular endothelial growth factor; $\mathrm{PPV}=$ pars plana vitrectomy.

The mean CST significantly increased from 263.57 microns (SD \pm 35.7, median: 275 microns) at baseline to 276.9 microns (SD \pm 52.9, median: 280 ) at 1 month of follow-up ( $p=0.049)$; and it remained stable compared with baseline at 2 months of follow-up (mean: 275.1 microns, SD \pm 39.3 , median: $279 ; \mathrm{p}=0.157$ ) and at 3 months of follow-up (mean: 275.4 microns, SD \pm 35.6 , median: 280; $p=0.064$ ). At 6 months of follow-up, the mean CST remained stable in 274.57 microns ( $S D \pm 48.7$, median: 277 microns) without significant differences from baseline data $(p=0.088)$.

The time to the first postoperative treatment indicated for DME since cataract surgery was 106.7 days (SD \pm 70.6 , median: 120). Eleven patients $(26.2 \%)$ received intravitreal bevacizumab, two patients (3.8\%) received intravitreal triamcinolone, 3 patients (7.1\%) received MLP, in 1 patient (2.3) a YAG capsulotomy was performed, and 11 patients (26.2\%) did not receive any further treatment during the follow-up.

\section{Group 2: Co-ADJUVANT THERAPY WITH INTRAOPERATIVE BEVACIZUMAB}

At baseline, 35 patients (59.3\%) showed DMT in the OCT images; 15 patients (25.4\%) presented with cystic DME; and 6 patients (10.1\%) showed neurosensory detachment. In the FA images, focal edema was present in 27 patients (45.8\%) and diffuse in 25 patients (42.4\%). Macular ischemia was observed in 5 patients (8.5\%). No evidence of DME was found in two patients (3.4\%). Retinal status was normal in 3 patients (5.1\%); mild NPDR in 15 patients (25.4\%); moderate NPDR in 10 patients (16.9\%); severe NPDR in 10 patients (16.9\%); and PDR in 11 patients (18.6\%).

The mean logMAR BCVA improved significantly from 0.80 (SD \pm 0.48 , median: 0.70) at baseline to 0.54 ( $S D \pm 0.42$, median: 0.50) at 1 month of follow-up ( $p<0.001)$; and maintained the significant visual gain compared with baseline at 2 months of follow-up (mean: 0.52 , SD \pm 0.42 , median: 0.50; $p<0.001$ ), and at 3 months of follow-up (mean: 0.49, SD \pm 0.42 , median: 0.40; $p<0.001$ ). At 6 months of follow-up, the mean BCVA was 0.54 (SD \pm 0.45 , median: 0.50), showing significant differences from baseline data $(p<0.001)$.

The mean CST increased from 316.02 microns (SD \pm 100.4 , median: 309 microns) at baseline to 334.63 microns (SD \pm 130.8 , median: 279.5 ) at 1 month of follow-up ( $p=0.039)$; and remained stable when compared with baseline at 2 months of follow-up (mean: 334.36 microns, SD \pm 174.1 , median, 242; $\mathrm{p}=0.248$ ), and at 3 months of follow-up (mean: 286.63 microns, $S D \pm 98.3$, median: 248; $\mathrm{p}=0.852$ ). At 6 months of follow-up, the mean CST remained stable in 339.56 microns (SD \pm 145.3 , median: 278 microns) ( $p=0.184$ ) without significant differences from baseline data.

The time to the first postoperative treatment indicated for DME since cataract surgery was 150.6 days (SD \pm 137.4, median: 160). Twenty-eight patients (42.4\%) received intravitreal treatment with bevacizumab, 7 patients (11.9\%) with triamcinolone, and 5 patients (8.5\%) with dexamethasone implant (Ozurdex $\left.{ }^{\oplus}\right)$. Two patients (3.4\%) received $M L P$, and 24 patients (40.6\%) did not receive any treatment during the follow-up.

\section{GROUP 3: Co-ADJUVANT THERAPY WITH INTRAOPERATIVE TRIAMCINOLONE}

At baseline 25 patients (67.6\%) showed DMT in the OCT images; 5 patients (13.5\%) cystoid DME; and two patients (5.4\%) neurosensory detachment. In the FA images, DME corresponded with focal edema in 14 patients (37.8\%) and diffuse edema in 13 patients (35.1\%). Macular ischemia was observed in 5 patients (13.5\%). No signs of DME were found in 5 patients (13.5\%). No patient showed a normal retinal status at baseline; mild NPDR was found in 3 patients (8.1\%); moderate NPDR in 5 patients (13.5\%); severe NPDR in 9 patients (24.3\%); and PDR in 20 patients (54.1\%).

The mean logMAR BCVA improved significantly from 1.0 (SD \pm 0.40 , median: 1.0) at baseline to 0.48 (SD \pm 0.37 , median: 0.40 ) at 1 month of follow-up ( $p<0.001)$; and maintained the significant visual gain compared with baseline at 2 months of follow-up (mean: 0.45, SD \pm 0.38 , median: $0.35 ; \mathrm{p}<0.001$ ); and at 3 months of follow-up (mean: $0.42, S D \pm 0.31$, median: $0.40 ; p<0.001)$. At 6 months of follow-up, the mean BCVA was 0.46 (SD \pm 0.34 , median: 0.40), showing significant differences from baseline data $(p<0.001)$.

The mean CST significantly decreased from 259.18 microns (SD \pm 97.9; median, 239 microns) at baseline to 243.97 microns (SD \pm 69.6; median, 236) at 1 month of follow-up ( $p=0.038$ ); and remained stable when compared with preoperative data at 2 months of follow-up (mean: 251.42 microns, SD \pm 63 , median: 246; $\mathrm{p}=0.478$ ) and at 3 months of follow-up (266.97 microns, SD \pm 66.7 , median: 253; $\mathrm{p}=0.340$ ). At 6-month follow-up, the CST increased to 282.21 microns (SD \pm 87.24 , median: 257 microns) with significant differences from baseline $(p=0.044)$.

The time to the first postoperative treatment indicated for DME since cataract surgery was 191.05 days (SD \pm 118.4 ; median, 189). Four patients $(10.8 \%)$ received intravitreal treatment with bevacizumab, 1 patient $(2.7 \%)$ received intravitreal treatment with triamcinolone, 15 patients $(40.5 \%)$ received macular laser therapy, two patients recei- 
ved pan-retinal photocoagulation therapy and 16 patients $(43.2 \%)$ did not receive any treatment during the follow-up.

\section{INTERGROUP COMPARISON}

There were no significant differences between the 3 groups in gender $(p=0.911)$, age $(p=0.433)$, and previous history of stroke $(p=0.284)$ or myocardial infarction $(p=0.395)$. However, there were statistically significant differences between the 3 groups regarding the presence of systemic arterial hypertension $(p<0.001)$; systemic glycemic control therapy $(p<0.001)$; duration of diabetes $(p<0.001)$; level of HbA1c $(p=0.004)$; baseline DR grading $(p<0.001)$; the frequency of previous treatment with anti-VEGF $(p<0.001)$, triamcinolone $(p<0.001)$ and MLP $(p<0.001)$; and prevalence of DME evaluated by OCT and FA $(p<0.001)$. There were significant differences in the intergroup comparison in the number of untreated patients prior to the cataract removal between Group 2 and Groups 1 and $3(p<0.001)$, but no significant difference was observed between Groups 1 and $3(p=0.156)$.

Statistically significant differences in the baseline BCVA between the 3 groups were evidenced ( $p=0.008$ ). These significant differences were also present in the final BCVA outcomes $(p<0.001)$. The mean visual gain was 0.68 (SD \pm 0.41 ; median: 0.60 ) in Group 1; 0.26 (SD \pm 0.46; median: 0.10) in Group 2; and 0.51 (SD \pm 0.43 ; median: 0.50) in Group 3. We found significant differences in the intergroup comparison between the 3 groups $(p<0.001)$, and between Group 2 and Groups 1 and 3 ( $p<0.001$ and $p=0.009$ respectively), but no significant differences were observed between Groups 1 and $3(p=0.79)$.

There were also statistically significant differences in the baseline CST between the 3 groups $(p=0.001)$, which were also present in the final CST $(p=0.005)$.

Finally there were no significant differences in the time when the physicians indicated the first treatment for DME after cataract surgery between the 3 groups ( $p=0.121$ ).

No ocular adverse event or significant ocular inflammatory reaction was reported in any of the 3 groups. Functional and anatomical results are summarized in table 2 .

\section{DISCUSSION}

The presence of postoperative macular edema after cataract surgery in diabetic patients may be related to the cataract surgery itself (so called pseudophakic cystoid macular edema, PCME) or to the underlying diabetic condition. The differentiation between both types is challenging. Whereas PCME tends to resolve spontaneously, DME frequently persists or increases following surgery ${ }^{(9,11)}$.

The incidence of clinical significant PCME after uncomplicated cataract surgery in the healthy population has been reported to be $0.1-2 \%$ of cases $^{(12,13)}$, whereas in diabetic patients the incidence of macular thickening after cataract surgery may rise to $10-81 \%(8,9,12,14)$. Factors reported to be associated with an increased risk for developing macular thickening after uneventful phacoemulsification in diabetic patients are DR stage, presence of DME, history of previous treatments, level of $\mathrm{HbA} 1 \mathrm{c}$ and duration of diabetes of more than 10 years ${ }^{(8)}$. Our results are consistent with these data, as we found a significant correlation between all those characteristics and both the final BCVA and CST.

Prophylaxis of macular thickening following cataract extraction in diabetic patients is a controversial issue. Intravitreal anti-VEGF (bevacizumab or ranibizumab) ${ }^{(15-20)}$ and intravitreal steroids (triamcinoIone acetonide or dexamethasone implant)(20-22) have been reported to achieve positive anatomical and functional results when injected immediately after the surgical procedure. More recently, the efficacy of topical non-steroidal anti-inflammatory drugs has also been reported $^{(23)}$.

In the present study, we found a significant postoperative retinal thickness decrease in the group treated with $4 \mathrm{mg} / 0.1 \mathrm{ml}$ of intraoperative triamcinolone, but during the follow-up these patients showed a significant increase in CST. On the other hand, the group with no co-adjuvant treatment and that with co-adjuvant therapy with $1.25 \mathrm{mg} / 0.05 \mathrm{ml}$ of bevacizumab showed a significant increase in the CST during the follow-up. We hypothesize that intravitreal triamcinolone administration may play a positive role in controlling the acute inflammatory factors that are released following cataract removal. The increase in the CST in the group of patients injected intraoperatively with bevacizumab is consistent with the results achieved by Rauen et al. ${ }^{(17)}$, who did not find a positive anatomical response with intraoperative ranibizumab, in contrast to other similar studies ${ }^{(15-19)}$ These results may be related to the high percentage of patients (84.7\%) previously treated for DME in this group, as it is known that the presence of DME before the cataract removal is a risk factor for developing macular thickening with this surgical procedure. Nevertheless, we found dissociation between anatomical and functional outcomes, as we found significant BCVA improvement after cataract extraction in all the study groups.

The results of the present study may suggest that patients with lower DR severity and absence of preoperative DME achieve the better visual outcomes. These results are consistent with previous reports ${ }^{(8,9)}$. On the other hand, patients with a higher grade of DR and previously treated DME showed less visual gain but the increase in BCVA was still statistically significant. We hypothesize that due to the baseline differences between groups, patients without co-adjuvant treatment or treated intraoperatively with triamcinolone achieved significant higher visual gain. Finally, all the patients included in the present study significantly improved BCVA, thus the cataract surgery may be a relevant approach to be considered in such cases.

The patients with DME at baseline and previous history of different treatments for DME were preferably injected intraoperatively with bevacizumab by the responsible physician, whereas patients with previously untreated DME were preferably treated with intraoperative triamcinolone. Otherwise, in patients with no DME at baseline and no previous treatments the physicians preferred not to provide any co-adjuvant therapy. We cannot offer an accurate intergroup comparison, but we did identify these preferred practice patterns

Table 2. Intergroup comparison of the functional and anatomic results

\begin{tabular}{|c|c|c|c|c|}
\hline & Group 1 & Group 2 & Group 3 & $\mathbf{p}$ \\
\hline Mean baseline BCVA (logMAR) & $0.82(\mathrm{SD} \pm 0.43)$ & $0.80(\mathrm{SD} \pm 0.48)$ & $1.0(S D \pm 0.40)$ & $p=0.008$ \\
\hline Mean final BCVA (logMAR) & $0.14(S D \pm 0.23)$ & $0.54(S D \pm 0.45)$ & $0.46(S D \pm 0.34)$ & $p<0.001$ \\
\hline Mean visual gain & $0.68(S D \pm 0.41)$ & $0.26(S D \pm 0.46)$ & $0.51(S D \pm 0.43)$ & $p<0.001$ \\
\hline Mean baseline CST (microns) & $263.57(S D \pm 35.70)$ & $316.02(S D \pm 100.4)$ & $259.18(S D \pm 69.6)$ & $p=0.001$ \\
\hline Mean final CST (microns) & $274.57(S D \pm 48.70)$ & $339.56(S D \pm 145.3)$ & $282.21(S D \pm 87.24)$ & $p=0.005$ \\
\hline
\end{tabular}

ANOVA test.

$\mathrm{SD}=$ standard deviation; $\mathrm{BCVA}=$ best-corrected visual acuity; $C S T=$ central subfield thickness; logMAR= logarithm of minimum angle of resolution. 
depending on the presence of previous DME and treatment administration before cataract extraction.

\section{CONCLUSION}

The limitations of the present study include its uncontrolled, retrospective and non-randomized nature. This has led to important differences in epidemiological and clinical factors between the different groups. The differences the presence of systemic arterial hypertension, systemic glycemic control therapy, duration of diabetes and level of $\mathrm{HbA} 1 \mathrm{c}$ at baseline may influence our results. However, our results are consistent with previous reports showing that DR grading and the presence of DME before cataract extraction may be related to a higher rate of DME after phacoemulsification. The relatively short-term follow-up is another limiting factor of the present study. Further prospective, randomized studies are warranted in order to analyze the efficacy of the different approaches.

In summary, our results suggest that cataract surgery in diabetic patients is an efficient procedure, resulting in highly significant BCVA improvement. This study may provide evidence to support the use of intravitreal triamcinolone or bevacizumab at the time of cataract surgery in cases with preexistent DME or moderate-severe NPDR. We can conclude that the visual outcomes after cataract surgery in diabetic patients may depend on the previous DR stage and the presence of DME, and the use of intravitreal co-adjuvants as triamcinolone or bevacizumab may optimize functional outcomes in these cases.

\section{REFERENCES}

1. Klein R, Knudtson MD, Lee KE, Gangnon R, Klein BE The Wisconsin Epidemiologic Study of Diabetic Retinopathy XXIII: the twenty-five-year incidence of macular edema in persons with type 1 diabetes. Ophthalmology. 2009;116(3):497-503.

2. Querques G, Bux AV, Martinelli D, laculli C, Del Curatolo MV, Delle Noci N. Short-term fluctuation of diabetic macular edema after intravitreal ranibizumab injection. Retina. 2009;29(9):1274-81.

3. Nguyen QD, Shah SM, Heier JS, Do DV, Lim J, Boyer D, Abraham P, Campochiaro PA; READ-2 Study Group. Primary End Point (Six Months). Results of the Ranibizumab for Edema of the mAcula in diabetes (READ-2) study. Ophthalmology. 2009;116(11): 2175-81.

4. Nguyen QD, Shah SM, Khwaja AA, Channa R, Hatef E, Do DV, Boyer D, Heier JS, Abraham P, Thach AB, Lit ES, Foster BS, Kruger E, Dugel P, Chang T, Das A, Ciulla TA, Pollack JS, Lim JI, Eliott D, Campochiaro PA; READ-2 Study Group. Two-year outcomes of the ranibizumab for edema of the mAcula in diabetes (READ-2) study. Ophthalmology. 2010;117(11):2146-51.

5. Diabetic Retinopathy Clinical Research Network, Elman MJ, Aiello LP, Beck RW, Bressler NM, Bressler SB, Edwards AR, Ferris FL $3^{\text {rd }}$, Friedman SM, Glassman AR, Miller KM, Scott IU, Stockdale CR, Sun JK. Randomized trial evaluating ranibizumab plus prompt or deferred laser or triamcinolone plus prompt laser for diabetic macular edema. Ophthalmology. 2010;117(6):1064-77. Comment in: Ophthalmology. 2010;117(6):1059-60.

6. Mitchell P, Bandello F, Schmidt-Erfurth $U$, Lang GE, Massin P, Schlingemann RO, Sutter F, Simader C, Burian G, Gerstner O, Weichselberger A; RESTORE study group. The RESTORE study: ranibizumab monotherapy or combined with laser versus laser monotherapy for diabetic macular edema. Ophthalmology. 2011;118(4):615-25.

7. Boyer DS, Faber D, Gupta S, Patel SS, Tabandeh H, Li XY, Liu CC, Lou J, Whitcup SM; Ozurdex CHAMPLAIN Study Group. Dexamethasone intravitreal implant for treatment of diabetic macular edema in vitrectomized patients. Retina. 2011;31(5):915-23. Comment in: Retina. 2012;32(8):1695-6; author reply 1696-7.

8. Kim SJ, Equi R, Bressler NM. Analysis of macular edema after cataract surgery in patients with diabetes using optical coherence tomography. Ophthalmology. 2007; 114(5):881-9.

9. Dowler JG, Sehmi KS, Hykin PG, Hamilton AM. The natural history of macular edema after cataract surgery in diabetes. Ophthalmology. 1999;106(4):663-8.

10. Ip MS, Domalpally A, Hopkins JJ, Wong P, Ehrlich JS. Long-term effects of ranibizumab on diabetic retinopathy severity and progression. Arch Ophthalmol. 2012;130(9): 1145-52.

11. Kwon SI, Hwang DJ, Seo JY, Park IW. Evaluation of changes of macular thickness in diabetic retinopathy after cataract surgery. Korean J Ophthalmol. 2011;25(4):238-42.

12. Mentes J, Erakgun T, Afrashi F, Kerci G. Incidence of cystoid macular edema after uncomplicated phacoemulsification. Ophthalmologica. 2003;217(6):408-12.

13. Eriksson U, Alm A, Bjärnhall G, Granstam E, Matsson AW. Macular edema and visual outcome following cataract surgery in patients with diabetic retinopathy and controls. Graefes Arch Clin Exp Ophthalmol. 2011;249(3):349-59.

14. Pollack A, Leiba H, Bukelman A, Oliver M. Cystoid macular oedema following cataract extraction in patients with diabetes. Br J Ophthalmol. 1992;76(4):221-4.
15. Lanzagorta-Aresti A, Palacios-Pozo E, Menezo Rozalen JL, Navea-Tejerina A. Prevention of vision loss after cataract surgery in diabetic macular edema with intravitreal bevacizumab: a pilot study. Retina. 2009; 29(4):530-5. Comment in: Retina. 2010;30(8): 1328-9; author reply 1329

16. Takamura Y, Kubo E, Akagi Y. Analysis of the effect of intravitreal bevacizumab injection on diabetic macular edema after cataract surgery. Ophthalmology. 2009;116(6):1151-7. Comment in: Ophthalmology. 2010;117(4):849; author reply 849-50.

17. Rauen PI, Ribeiro JA, Almeida FP, Scott IU, Messias A, Jorge R Intravitreal injection of ranibizumab during cataract surgery in patients with diabetic macular edema. Retina. 2012;32(9):1799-803.

18. Fard MA, Yazdanei Abyane A, Malihi M. Prophylactic intravitreal bevacizumab for diabetic macular edema (thickening) after cataract surgery: prospective randomized study. Eur J Ophthalmol. 2011;21(3):276-81. Comment in: Eur J Ophthalmol. 2012;22(3): 513; author reply 514.

19. Akinci A, Batman C, Ozkilic E, Altinsoy A. Phacoemulsification with intravitreal bevacizumab injection in diabetic patients with macular edema and cataract. Retina. 2009; 29(10):1432-5.

20. Akinci A, Muftuoglu O, Altınsoy A, Ozkılıc E. Phacoemulsification with intravitreal bevacizumab and triamcinolone acetonide injection in diabetic patients with clinically significant macular edema and cataract. Retina. 2011;31(4):755-8.

21. Takata C, Messias A, Folgosa MS, Lucena LR, Lucena DR, Scott IU, Jorge R. Intravitreal injection versus subtenon infusion of triamcinolone acetonide during cataract surgery in patients with refractory diabetic macular edema. Retina. 2010;30(4):562-9.

22. Agarwal A, Gupta V, Ram J, Gupta A. Dexamethasone intravitreal implant during phacoemulsification. Ophthalmology. 2013;120(1):211

23. Singh R, Alpern L, Jaffe GJ, Lehmann RP, Lim J, Reiser HJ, et al. Evaluation of nepafenac in prevention of macular edema following cataract surgery in patients with diabetic retinopathy. Clin Ophthalmol. 2012;6:1259-69.

\section{Appendix}

The following investigators belong to the Pan-American Collaborative Retina Study Group (PACORES):

The Pan-American Collaborative Retina Study Group (PACORES)*-

L. Wu (PI), Instituto de Cirugia Ocular, San Jose, Costa Rica; J. F. Arevalo (PI), I Kozak,V. Gupta, S. Al-Rashaed, E. Al-Kahtani, The King Khaled Eye Specialist Hospital, Riyadh, Kingdom of Saudi Arabia, and the Wilmer Eye Institute, Johns Hopkins University, Baltimore, Maryland, USA; M. A. Serrano (PI), A. F. Lasave, Clinica Oftalmologica Centro Caracas and the Arevalo-Coutinho Foundation for Research in Ophthalmology, Caracas, Venezuela; M. Farah (PI), M. Maia, F. M. Penha, E. B. Rodrigues, Universidade Federal de São Paulo - Departamento de Oftalmologia - Instituto da Visão - Sao Paulo, Brazil; V. Morales-Canton (PI), J. Fromow-Guerra, J.L. Guerrero-Naranjo, J. Dalma-Weiszhausz, M. A. Martinez-Castellanos, Asociación para Evitar la Ceguera en México, Mexico City, Mexico; H. Quiroz-Mercado (PI), R. Velez-Montoya, University of Colorado, School of Medicine, Denver, Colorado, USA; F. J. Rodriguez (PI), F. E. Gomez, A. C. Brieke, Fundacion Oftalmologica Nacional, Universidad del Rosario, Bogota, Colombia; M.H. Berrocal (PI), V. Cruz-Villegas, University of Puerto Rico, San Juan, Puerto Rico; F. Graue-Wiechers (PI), D. Lozano-Rechy, E. Ariza-Camacho, Fundacion Conde Valenciana, Mexico City, Mexico; J.A. Roca (PI), R.G. Chico, Clínica Ricardo Palma, Lima, Peru; M. J. Saravia (PI), A. Schlaen, A. Lupinacci, M. N. Gabin, Hospital Universitario Austral, Buenos Aires, Argentina; M. Avila (PI), L. Carla, Universidade Federal de Goiás - Departamento de Oftalmologia - Goiânia, Brazil; J. Cardillo (PI), Hospital de Olhos de Araraquara, and the Universidade de Sao Paulo, Sao Paulo, Brazil; C. Carpentier (PI), J. Verdaguer T., J.I. Verdaguer D., G. Sepúlveda, Fundacion Oftalmologica Los Andes, Santiago de Chile, Chile; A. Alezzandrini (PI), B. Garcia, G. Bregliano, OFTALMOS, Catedra de Oftalmologia, Universidad de Buenos Aires, Buenos Aires, Argentina; G. Alvira (PI), P. Flor, F, Jaramillo, Hospital Metropolitano, Quito, Ecuador; M. Diaz-Llopis (PI), R. Gallego-Pinazo, D. Salom, R. Dolz-Marco, S. Martínez-Castillo, Hospital La Fe, Universidad de Valencia, Spain; M. Figueroa (PI), I. Contreras, D. Ruiz-Casas, Hospital Universitario Ramón y Cajal, Departamento de Retina, and VISSUM Madrid Mirasierra de Oftalmología Integral, Madrid, Spain.

${ }^{*} \mathrm{PI}=$ Principal Investigator 